\title{
OS JOVENS QUE NÃO TRABALHAM E NÃO ESTUDAM NO CONTEXTO DA PANDEMIA DA COVID-19 NO BRASIL'
}

Enid Rocha Andrade da Silva²

Fábio Monteiro Vaz ${ }^{3}$

\section{INTRODUÇÃO}

As importantes medidas tomadas para conter o contágio do vírus Sars-COV-2 no Brasil tiveram como consequência a redução do consumo e do investimento e a perda expressiva de postos de trabalho. Em relação ao mercado de trabalho, uma especificidade da atual crise foi o aumento da inatividade e, principalmente, do número de jovens desalentados, que desistiram de procurar emprego porque não têm esperanças de que irão encontrar. Ademais, essa crise tem um diferencial importante no que se refere a outras que a precederam. Além de impactar no mercado de trabalho, também interrompe o processo de construção de habilidades, como a continuidade da educação e da formação profissional, que são fundamentais para ampliar as chances de os jovens conquistarem um trabalho decente na fase de recuperação.

A paralisação das atividades escolares nas redes públicas de ensino alcançou grande parte dos jovens no país. Também aqueles que pagavam por sua própria educação podem ter tido a continuidade dos seus estudos prejudicada pela perda de suas ocupaçóes e pela consequente redução dos rendimentos familiares. Além disso, poucos jovens têm sido capazes de dar continuidade on-line à sua formação, não apenas pelas dificuldades de acesso à internet, marcada por muita desigualdade no Brasil, mas também pela necessidade de dedicar horas a mais nas tarefas de cuidados e de afazeres domésticos para suas famílias. Essa segunda razão afeta, sobretudo, as jovens mulheres que, devido à ausência de apoio no domicílio ou de espaços como a creche/ escola no período de isolamento social, tiveram que se ocupar mais intensamente do trabalho não remunerado no domicílio nesse período da pandemia.

Assim, se antes do cenário pandêmico, o Brasil já contava com um número considerável de jovens que não estudavam, não trabalhavam e não estavam em treinamento, as especificidades da crise Covid-19 agravam esse quadro, na medida em que contribuem para aumentar o contingente de jovens que interrompem seus estudos e param de buscar emprego, ampliando o grupo dos jovens nem-nem desengajados da força de trabalho. Sem trabalhar e sem estudar, esses indivíduos não estão acumulando capital humano, o que pode levar a perdas de rendimentos significativas e persistentes que comprometem suas trajetórias laborais ao longo da vida.

1. DOI: http://dx.doi.org/10.38116/bmt70/dossiea2

2. Técnica de planejamento e pesquisa na Diretoria de Estudos e Políticas Sociais (Disoc) do Ipea. E-mail: <enid.rocha@ipea.gov.br>.

3. Técnico de planejamento e pesquisa na Disoc/lpea.E-mail: <fabio.vaz@ipea.gov.br>. 
Para os jovens, o legado da crise sanitária pode durar décadas. Por essa razão, conhecer mais sobre suas vulnerabilidades, analisar suas diferentes motivaçóes para permanecerem sem estudar e sem trabalhar e compreender as transiçôes que realizam no período da pandemia são fundamentais para o desenho de políticas públicas que possam romper com o círculo vicioso presente na vida desses indivíduos que os leva a transitar, indefinidamente, entre longos período de inatividade e de inserção precária no mercado de trabalho.

Este texto propóe-se a discutir as vulnerabilidades dos jovens nem-nem ${ }^{4}$ no Brasil e o movimento destes em relação à força de trabalho no contexto da pandemia da Covid-19. Além desta introdução, este texto possui outras três seções. A seção 2 discute as diferentes categorias dos jovens que não estudam e não trabalham e avalia a dimensão desse problema no Brasil. A seção 3 tem como foco a análise das transições dos jovens nem-nem com relação à força de trabalho, como efeito da crise sanitária. Finalmente, a seção 4 traz as consideraçóes finais, destacando as principais conclusóes desta análise.

\section{A HETEROGENEIDADE DA CATEGORIA DOS JOVENS SEM ESTUDO E SEM TRABALHO NO BRASIL}

A ampla literatura a respeito dos nem-nem trouxe valiosas contribuiçóes que permitiram avançar muito na compreensão sobre os contornos dessa população. Inúmeros estudos já apontaram que as desigualdades de gênero, raça e renda marcam as trajetórias desses jovens na escola e no mundo do trabalho. Ser mulher, especialmente com filhos; ser pobre; ser negro; ter baixa escolaridade; e morar em domicílios com maior número de crianças, ou outra pessoa que exige cuidados aumentam expressivamente as chances de um jovem se tornar nem-nem por um curto ou longo período de sua vida. Os dados da Pesquisa Nacional por Amostra de Domicílios (PNAD) Contínua 2019, do Instituto Brasileiro de Geografia e Estatística (IBGE), mostram que essas características ainda se mantêm para a maior parte dos jovens que não estudam e não trabalham no Brasil.

Em 2019, o Brasil tinha 47,2 milhóes de jovens de 15 a 29 anos. Juntos, eles correspondiam a $28 \%$ da populaçáo acima de 15 anos e equivalem a quase a mesma fraçáo de população economicamente ativa (PEA). Porém, apesar de corresponderem a menos de um terço da força de trabalho, os jovens representavam mais da metade dos desocupados (54\%). Por ser um grupo diverso, delimitado por uma amplitude etária significativa, a inserção dos jovens no mercado de trabalho náo pode ser analisada como um todo, mas, sim, para cada grupo etário separadamente.

O gráfico 1 indica o quanto essas inserçóes são diversas. Na faixa etária de 15 a 17 anos, observa-se que a maioria dos jovens está fora do mercado de trabalho, muitos deles ainda concentrados exclusivamente nos estudos. De 18 a 24 anos, nota-se um período de transição, com grande parcela se inserindo no mercado de trabalho, sendo $53 \%$ ocupados e $17 \%$ à

4. Neste texto, os jovens que não estudam e não trabalham são referidos de diferentes formas: jovens sem estudo sem trabalho; jovens nem-nem e jovens sem trabalhar e sem estudar. Entretanto, independente da forma de referência, reconhece-se que estar sem trabalhar e sem estudar é uma situação em que os jovens se encontram e não que os define. 
procura de ocupação. Mas, há ainda uma fração significativa de jovens fora da força de trabalho (30\%). Por fim, a inserção dos jovens dos 25 aos 29 anos se assemelha muito à dos adultos não jovens, com apenas $18 \%$ fora da força de trabalho. Apesar das diferenças, o que se percebe como característica comum a todos esses jovens de faixas etárias distintas é a presença elevada da desocupação em comparação com a população não jovem.

\section{GRÁFICO 1}

\section{Força de trabalho e ocupação por faixa etária (2019)}

(Em \%)

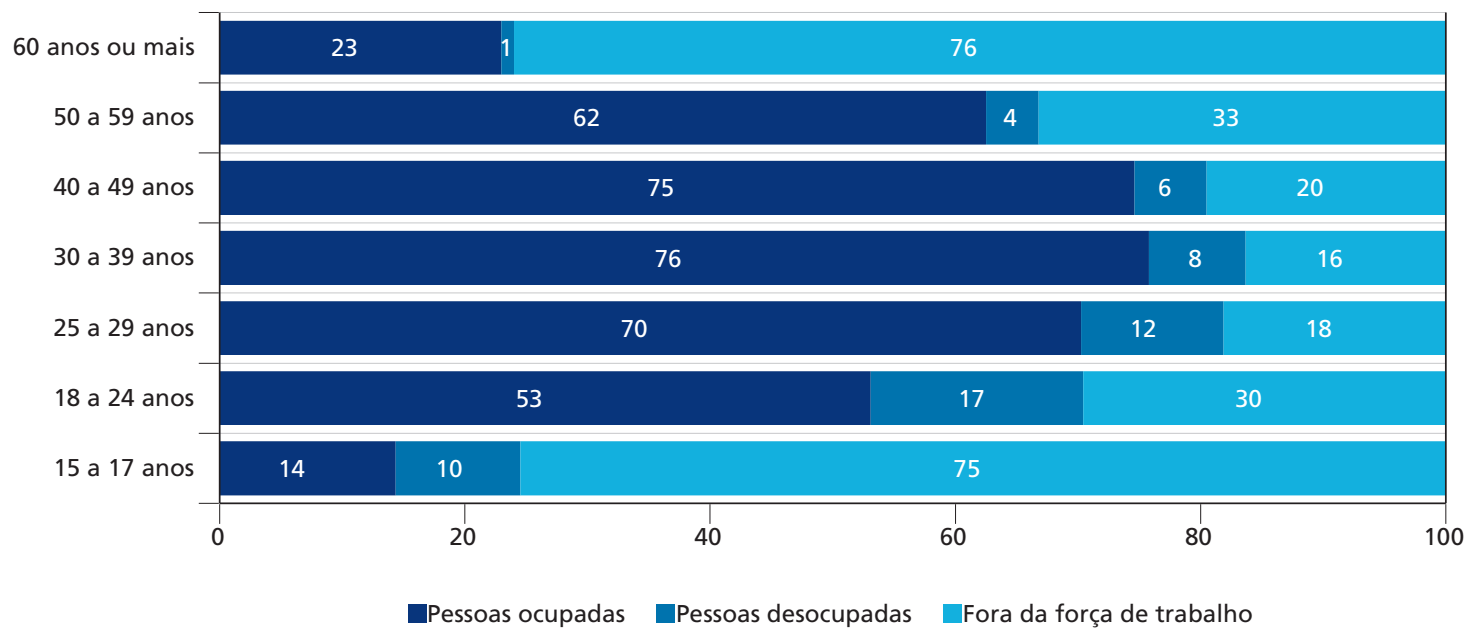

Fonte: PNAD Contínua 2019. Disponível em: <https://bit.ly/2SZmnHG>.

Elaboração dos autores.

Para aprofundar a caracterização da população jovem, iremos, a seguir, cruzar a condição de ocupação/atividade com a frequência à escola para identificar os jovens sem trabalho e sem estudo. Por frequência à escola, entende-se a educação formal obtida nos ensinos pré-escolar, fundamental, médio e superior. Porém, observe que, além da educação formal, é possível que grupos da força de trabalho estejam engajados em outras formas de ensino, como cursos de nível técnico (na modalidade subsequente e concomitante ao ensino médio), qualificação profissional ou pré-vestibular. ${ }^{5}$ Nesses casos, os jovens são classificados como não frequentando a escola. Isso ocorre porque as pesquisas domiciliares como a PNAD Contínua priorizam a captação da educação formal da população. As informações sobre frequência de cursos de nível técnico, qualificação profissional ou pré-vestibular, quando captadas, são feitas somente em suplementos especiais. ${ }^{6}$

5. A PNAD não considera como frequentando a escola a pessoa que frequentava somente curso de: qualificação profissional ou de formação inicial e continuada (FIC), ou de extensão cultural; técnico de nível médio na modalidade subsequente; técnico de nível médio na modalidade concomitante, caso já tenha terminado o ensino médio antes de concluir o ensino técnico de nível médio; pré-vestibular; sequencial de educação superior; de pós-graduação que não fosse de especialização de curso superior, mestrado ou doutorado; de alfabetização de adultos, de ensino fundamental e de ensino médio, ministrado por meio de rádio e de televisão ou por correspondência (IBGE, 2020).

6. No caso da PNAD Contínua, essas informações são captadas no suplemento de educação que é levado a campo junto ao questionário principal da pesquisa no segundo trimestre de cada ano. 
Essa indisponibilidade de informaçóes sobre estudo não formal nas pesquisas domiciliares na frequência desejada gera um problema de classificação, pois, segundo definições recentes (Eurofound, 2016), um jovem que frequenta um curso técnico está em treinamento e, portanto, não pode ser considerado um jovem sem trabalho e sem estudo. ${ }^{7}$ Especificamente no caso da PNAD Contínua, esse problema pode ser amenizado utilizando-se as respostas da questão sobre o motivo pelo qual não procurou trabalho ou não gostaria de ter trabalhado ou não estava disponivel para iniciar um trabalho. Entre os motivos passíveis de serem respondidos, um deles lista como estava estudando (curso de qualquer tipo ou por conta própria). Embora se possa reconhecer que tal resposta é muito ampla e pode ir além daquilo que normalmente se considera como treinamento, ela é uma aproximaçáo possível para captar os jovens que náo frequentam a escola e não fazem parte da força de trabalho, mas que estão se dedicando a cursos de nível técnico, qualificação profissional ou pré-vestibular.

O quadro 1 resume a classificação adotada neste estudo. Entre os desocupados, consideramse sem trabalho e sem estudo somente aqueles que náo frequentam a escola. ${ }^{8}$ Nesse grupo dos desocupados, não se leva em conta a dedicação a cursos de treinamento na definiçãa de quem é sem trabalho e sem estudo, pois náo é possível identificar essa informação para aqueles que estáo desocupados. Dessa forma, é provável que nesse grupo se encontrem jovens que estejam frequentando cursos fora da educação regular. Essa informação, por sua vez, está disponível e é utilizada para classificar a população que está fora da força de trabalho. Assim, segundo o critério adotado nesta análise, são classificados como sem trabalho e sem estudo fora da força de trabalho aqueles que não frequentam a escola ou que disseram que não procuraram trabalho, pois estavam frequentando cursos de qualquer tipo ou por conta própria.

QUADRO 1

Definição de jovens sem trabalho e sem estudo (nem-nem) e sua relação com a condição de ocupação/atividade

\begin{tabular}{|l|l|}
\hline \multicolumn{1}{|c|}{ Condição de ocupação/atividade } & \multicolumn{1}{c|}{ Estudo e trabalho } \\
\hline \multirow{2}{*}{ Pessoas ocupadas } & Estuda e trabalha. \\
\cline { 2 - 2 } Pessoas desocupadas & Somente trabalha. \\
\hline \multirow{2}{*}{ Fora da força de trabalho } & $\begin{array}{l}\text { Somente procura trabalho, sendo possível estar frequentando } \\
\text { outros cursos não incluídos na educação regular (nem-nem). }\end{array}$ \\
\cline { 2 - 2 } & Estuda e procura trabalho. \\
\hline & Somente estuda (escola). \\
\hline & Somente estuda (curso de qualquer tipo ou por conta própria). \\
\hline & Sem trabalho e sem estudo. \\
\hline
\end{tabular}

Elaboração dos autores.

7. Em inglês, not in education, employment, or training (NEET).

8. No Brasil, em geral, os estudos empíricos não consideram os jovens que buscam emprego como nem-nem. Nesta seção, como nas demais seções deste estudo, adota-se a definição da Organização Internacional do Trabalho (OIT), bem como do indicador 8.6.1 da meta 8.6 do Objetivo de Desenvolvimento Sustentável (ODS) 8, que incluem os desempregados entre os jovens nem-nem. 
Estabelecida a definição de sem trabalho e sem estudo, segue a questão: qual a distribuição dos jovens nas categorias de estudo e trabalho? O gráfico 2 mostra que, novamente, a inserção dos jovens difere muito de acordo com a faixa etária. Dos 15 aos 17 anos, a maioria dos jovens que estão fora da força de trabalho está somente estudando. Nessa faixa etária, a taxa ${ }^{9}$ dos jovens nem-nem é de apenas 7\%, sendo 5\% aqueles que estão sem estudar e sem trabalhar e 2\% aqueles que não estudam e só procuram trabalho. Para os jovens de 18 a 24 anos, porém, a situação é bem diferente, visto que a maioria já não está mais dedicada exclusivamente aos estudos, sendo observado o contrário: boa parte desses indivíduos está exclusivamente engajada em trabalhar ou sem procurar emprego. Note, todavia, que essa é uma fase de transição; por esse motivo, cerca de $15 \%$ dos jovens ainda se dedicam exclusivamente aos estudos.

GRÁFICO 2

Relação entre estudo e trabalho dos jovens (2019)

(Em \%)

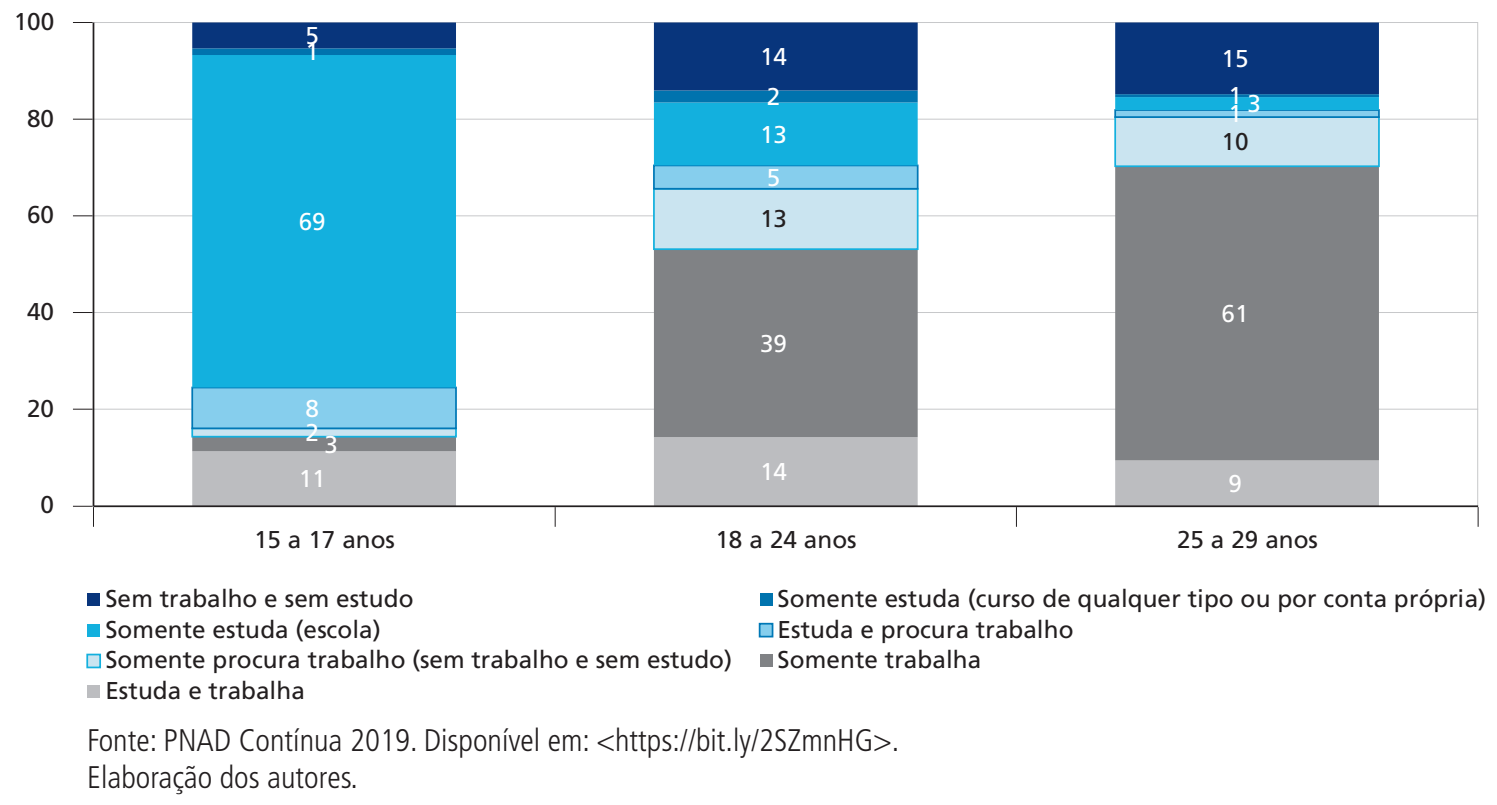

Como se percebe, para uma grande parcela dos jovens que saem da escola, a transição para o mercado de trabalho consiste em um problema, pois é justamente a partir dos 18 anos que a condição de sem trabalho e sem estudo se torna mais acentuada. A taxa dos jovens nem-nem é de $27 \%$ na faixa etária de 18 a 24 anos (13\% só procuram trabalho e 14\% são sem trabalho e sem estudo), o triplo da encontrada na faixa etária de 15 a 17 anos. Na faixa etária de 25 a 29 anos, os jovens nem-nem alcançam $25 \%$.

Analisando a incidência da condição nem-nem em diferentes grupos populacionais (gráfico 3), observa-se, conforme mostrado anteriormente, uma prevalência maior na faixa dos 18 aos 24 anos, mas também um predomínio alto entre jovens do sexo feminino (28\%), negros (26\%)

9. A taxa de jovens sem trabalho e sem estudo é definida como a razão do número de jovens nessa condição em relação à população total de jovens (Mascherini, 2019). 
e moradores da regiáo Nordeste (29\%). ${ }^{10}$ Os dados também confirmam as vulnerabilidades com relação à educação e à renda desses jovens, visto que a condição de sem trabalho e sem estudo acomete $46 \%$ dos jovens que se situam no primeiro décimo da distribuição de renda e $31 \%$ dos jovens que completaram ensino fundamental, mas que possuem ensino fundamental incompleto ou equivalente. Por fim, nota-se uma maior prevalência entre responsáveis/cônjuges com filhos (35\%) em comparação com jovens que são filhos ou enteados da pessoa responsável do domicílio.

\section{GRÁFICO 3}

\section{Incidência de jovens sem trabalho e sem estudo em grupos selecionados (2019)} (Em \%)

\section{$3 A$ - Mais vulneráveis}

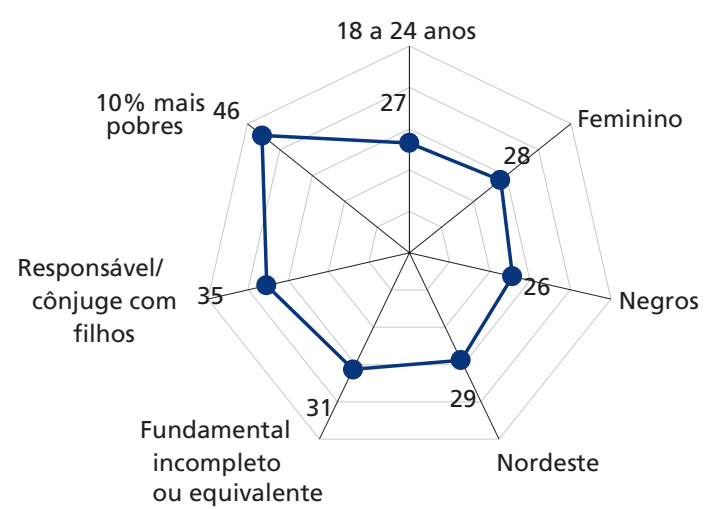

\section{B - Menos vulneráveis}

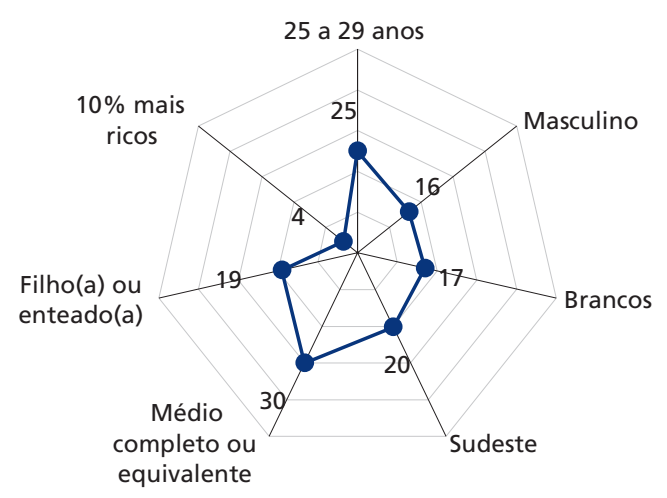

Fonte: PNAD Contínua 2019. Disponível em: <https://bit.ly/2SZmnHG>.

Elaboração dos autores.

Os dados no gráfico 3, apesar de mostrarem as características fundamentais dos jovens que não estudam e não trabalham e serem importantes para descortinar as principais desigualdades que afetam essa populaçáo, são muito gerais e escondem a enorme heterogeneidade que tem lugar no interior do grupo dos jovens sem estudo e sem trabalho no Brasil. Assim, por essa razão, não favorecem a elaboração de políticas públicas capazes de alcançar todos os jovens que estáo nessa condiçáo. Com o objetivo de dar visibilidade às diversas vulnerabilidades que afetam os diferentes grupos de nem-nem, esta seção analisa essa população, subdividindo-a em seis categorias, expostas no quadro $2 .^{11}$

10. Note que esses grupos que constam no gráfico 3 foram escolhidos por sua representatividade, e não necessariamente por serem aqueles com maior ou menor prevalência da condição de sem trabalho e sem estudo. Como exemplo, estima-se, na PNAD Contínua, que $66 \%$ dos jovens que não completaram nem o primeiro ano de estudo estão sem trabalho e sem emprego. Porém, a fração de jovens com esse nível de escolaridade é pequena em relação àqueles que possuem fundamental incompleto, sendo que esses últimos também possuem uma alta prevalência de jovens sem trabalho e sem emprego.

11. A categorização aqui utilizada foi construída com base em Mascherini (2019), que faz uma importante contribuição ao propor uma categorização que subdivide os jovens nem-nem de acordo com a principal razão/motivo para não estarem trabalhando ou procurando trabalho. 
QUADRO 2

Categorias de jovens sem trabalho e sem estudo

\begin{tabular}{|c|c|c|}
\hline Categorias & Definição & $\begin{array}{l}\text { Condição na } \\
\text { força de trabalho }\end{array}$ \\
\hline $\begin{array}{l}\text { Desempregados de } \\
\text { curto prazo }\end{array}$ & $\begin{array}{l}\text { Jovens desempregados, que procuram trabalho e que estão desempregados há } \\
\text { menos de um ano. }\end{array}$ & \multirow{2}{*}{$\begin{array}{l}\text { Incluídos da força } \\
\text { de trabalho }\end{array}$} \\
\hline $\begin{array}{l}\text { Desempregados de } \\
\text { longo prazo }\end{array}$ & $\begin{array}{l}\text { Jovens desempregados, que procuram trabalho e que estão desempregados há } \\
\text { mais de um ano. }\end{array}$ & \\
\hline $\begin{array}{l}\text { Indisponível devido } \\
\text { à saúde, gravidez ou } \\
\text { incapacidade }\end{array}$ & $\begin{array}{l}\text { Jovens que não procuram emprego ou não estão disponíveis para iniciar um } \\
\text { trabalho devido a doença ou incapacidade. }\end{array}$ & \multirow{4}{*}{$\begin{array}{l}\text { Fora da força de } \\
\text { trabalho }\end{array}$} \\
\hline $\begin{array}{l}\text { Indisponível devido } \\
\text { a responsabilidades } \\
\text { familiares }\end{array}$ & $\begin{array}{l}\text { Jovens que não estão procurando emprego ou que não estão disponíveis para } \\
\text { iniciar um novo emprego porque cuidam de crianças ou adultos incapacitados ou } \\
\text { têm outras responsabilidades familiares menos específicas. }\end{array}$ & \\
\hline Desencorajados & $\begin{array}{l}\text { Jovens que pararam de procurar trabalho porque acreditam que não há opor- } \\
\text { tunidades de emprego para eles. São na maioria jovens vulneráveis e com alto } \\
\text { risco de exclusão social, com grande probabilidade de obter maus resultados no } \\
\text { emprego ao longo de suas vidas profissionais e com alto risco de desligamento } \\
\text { ao longo da vida. }\end{array}$ & \\
\hline Outros $^{1}$ & $\begin{array}{l}\text { Inclui os jovens que, na PNAD Contínua, responderam às seguintes motivações } \\
\text { para não trabalho: "Não quer trabalhar ou é aposentado"; "Não tinha experiên- } \\
\text { cia profissional ou qualificação"; "Acha que não vai encontrar trabalho por ser } \\
\text { muito jovem ou idoso"; " "Estava aguardando resposta de medida tomada para } \\
\text { conseguir trabalho"; e "Outros motivos". }\end{array}$ & \\
\hline
\end{tabular}

Fonte: Mascherini (2019).

Elaboração dos autores.

Nota: ' Diferente da proposta de Mascherini, na adaptação para o Brasil, as categorias reentrantes e outros inativos foram aglutinadas em outros devido ao número reduzido de casos.

O gráfico 4 apresenta a composição dos jovens nem-nem de 15 a 29 anos e destaca o peso de cada um dos subgrupos detalhados no quadro 2. Em 2019, quase 60\% dos jovens nem-nem do país estavam fora da força de trabalho e já não buscavam emprego. Desses, 13\% eram desencorajados; $24 \%$ não estavam disponíveis para trabalhar por serem responsáveis pelos afazeres domésticos e/ou por terem que cuidar de pessoas no domicílio; $9 \%$ não trabalhavam por indisponibilidade decorrente de saúde ou gravidez; e 11\% estavam sem trabalhar e sem estudar por motivos diferentes aos citados anteriormente. Cerca de $40 \%$ dos jovens nem-nem faziam parte da força de trabalho na qualidade de jovens desocupados de curto prazo $(24 \%)$ e desocupados de longo prazo (19\%).

Todos esses subgrupos de nem-nem carregam algum tipo de vulnerabilidade, cuja magnitude varia em funçáo das maiores ou menores dificuldades que os jovens teriam que enfrentar para retomar ao mercado de trabalho, caso desejassem. Do ponto de vista do retorno ao mercado de trabalho, os jovens desencorajados apresentariam maiores dificuldades de fazerem o percurso de volta em função do maior tempo em que permaneceram inativos. 
GRÁFICO 4

Distribuição dos jovens sem trabalho e sem estudo por categorias e faixa etária (2019) (Em \%)

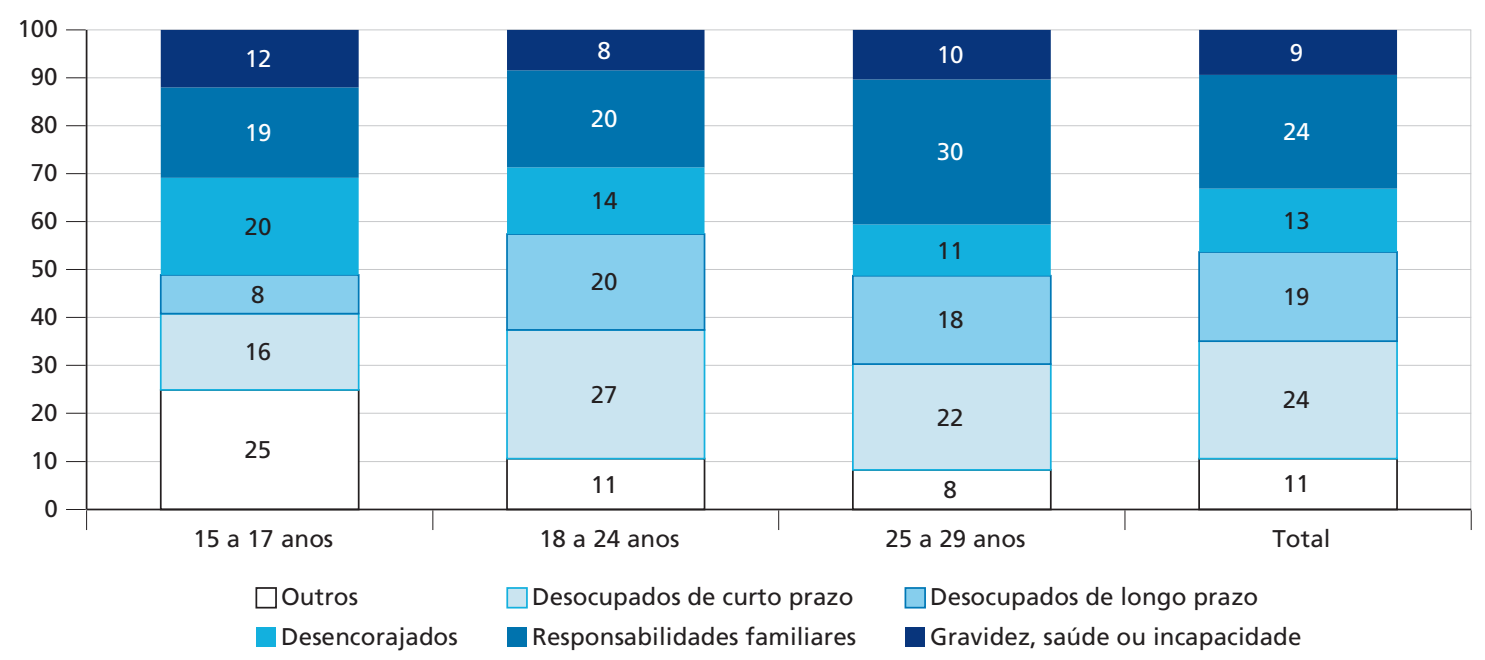

Fonte: PNAD Contínua 2019. Disponível em: <https://bit.ly/2SZmnHG>.

Elaboração dos autores.

Isso também ocorreria com o grupo das jovens nem-nem por responsabilidades familiares, que são extremamente vulneráveis, cujo retorno ao mercado de trabalho e à escola dependem da oferta pública de serviços públicos de cuidados para crianças, adultos e idosos com incapacidades. Por sua vez, os jovens indisponíveis por doença ou incapacidade são também considerados extremamente vulneráveis, porque estão impossibilitados de realizar trabalho remunerado pelo tempo em que o problema de saúde persistir. Muitas vezes pela vida toda. Impedidos de auferirem renda por meio do trabalho, tornam-se muito vulneráveis, pois teráo sua sobrevivência dependente de apoio assistencial e/ou familiar até que se recuperem e possam retomar suas trajetórias laborais.

É importante registrar que, mesmo entre os nem-nem que integram a força de trabalho, existe diferença no nível de vulnerabilidade. Aqueles que se encontram desocupados por longo prazo são considerados mais vulneráveis que os de curto prazo, visto que enfrentarão mais dificuldades de encontrarem inserção qualificada no mercado de trabalho em função do maior tempo nesta situação. No longo período em que permanecerem desocupados, esses jovens terão suas competências profissionais desvalorizadas e sua saúde mental comprometida, aumentando o risco de se tornarem jovens desencorajados.

Como apontado anteriormente, ser mulher, ser responsável ou cônjuge com filhos, ser negro, ter baixa escolaridade e morar em domicílio de baixa renda aumentam muito a probabilidade do jovem de ficar sem estudo e sem trabalho. No entanto, o que os dados do gráfico 5 acrescentam é que, mesmo considerando que todos os jovens nem-nem apresentam vulnerabilidades distintas, é possível encontrar marcadores sociais que agravam as desigualdades entre os vários subgrupos de nem-nem. Por exemplo, os jovens nem-nem com ensino médio completo ou equivalente concentram-se mais nos subgrupos dos desocupados - tanto de curto 
quanto de longo prazo - em relação aos demais subgrupos. Ainda em relação à escolaridade, observa-se uma concentração de jovens que não completaram o ensino fundamental entre aqueles que se encontram indisponíveis devido a gravidez, saúde ou incapacidade.

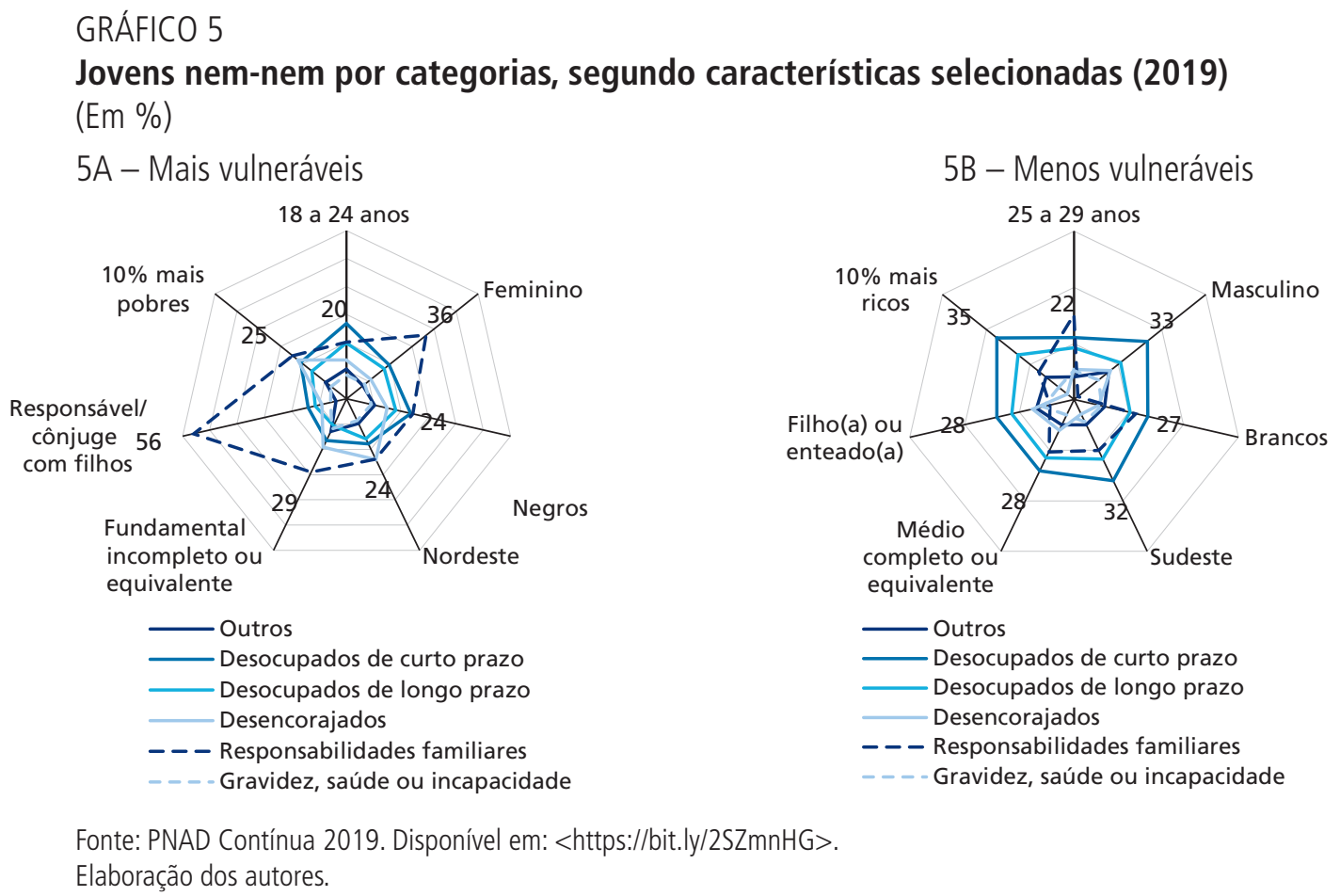

Além disso, há uma fração menor de jovens de domicílios de baixa renda (isto é, do primeiro décimo da distribuição de renda domiciliar per capita) entre os desocupados e uma maior concentração desses jovens entre os desencorajados e indisponíveis devido a responsabilidades familiares, quando comparados com os jovens mais abastados. Em relação ao gênero e à raça/cor, que são duas características definidoras das desigualdades sociais no Brasil, os dados mostram que jovens sem trabalho e sem estudo pretos e pardos (negros) se concentram mais entre os desencorajados do que os brancos. Quanto ao sexo, destaca-se a desigualdade de gênero na realização do trabalho não remunerado no domicílio, uma vez que $36 \%$ das jovens nem-nem estão nessa situação devido a responsabilidades familiares. Assim, pode-se concluir que os nem-nem fora da força de trabalho são os mais vulneráveis.

\section{A TRANSIÇÃO DOS JOVENS NEM-NEM NO PERÍODO DA PANDEMIA DA COVID-19}

Guimarães, Marteleto e Alves (2016), ao estudarem trajetórias de jovens brasileiros, demonstraram que a transição escola-trabalho está longe de poder ser considerada linear. Esses autores revelam que transitar entre situaçóes de emprego, desemprego e inatividade é um movimento habitual na trajetória dos jovens. Por essa razão, pesquisas longitudinais são fundamentais para avançar na compreensão dos movimentos realizados por esses jovens 
entre a escola e o mercado de trabalho. A partir das contribuiçóes desses autores, conclui-se que a inatividade, como a que caracteriza a situação dos nem-nem, estudada neste texto, não é permanente na vida dos jovens.

Ao longo de suas trajetórias laborais e educacionais, os jovens vivenciam várias situaçôes que podem incluir apenas trabalhar, conciliar trabalho com estudo, só estudar ou ficar sem estudar e sem trabalhar por determinado período. Considerando as diferentes categorias dos jovens sem estudo e sem trabalho, discutidas aqui, conjugadas com a natural impermanência das situaçóes dos jovens no mercado de trabalho, o objetivo desta seção será analisar os movimentos que os jovens nem-nem realizaram em torno da força de trabalho como efeito da crise sanitária da Covid-19.

Análises sobre o desempenho do mercado de trabalho durante a pandemia mostraram uma queda expressiva da ocupação entre os jovens a partir do segundo trimestre de 2020, que não é acompanhada de um aumento na desocupação. De fato, os jovens que perderam seu trabalho parecem migrar imediatamente para fora da força de trabalho ${ }^{12}$ (gráfico 6). Como será mostrado nesta seção, entre os nem-nem também se observou uma migração dos grupos dos nem-nem desocupados na direção dos grupos de nem-nem, que se situam fora da força de trabalho.

GRÁFICO 6

Proporção trimestral da condição de ocupação e atividade dos jovens (2012-2020) (Em \%)

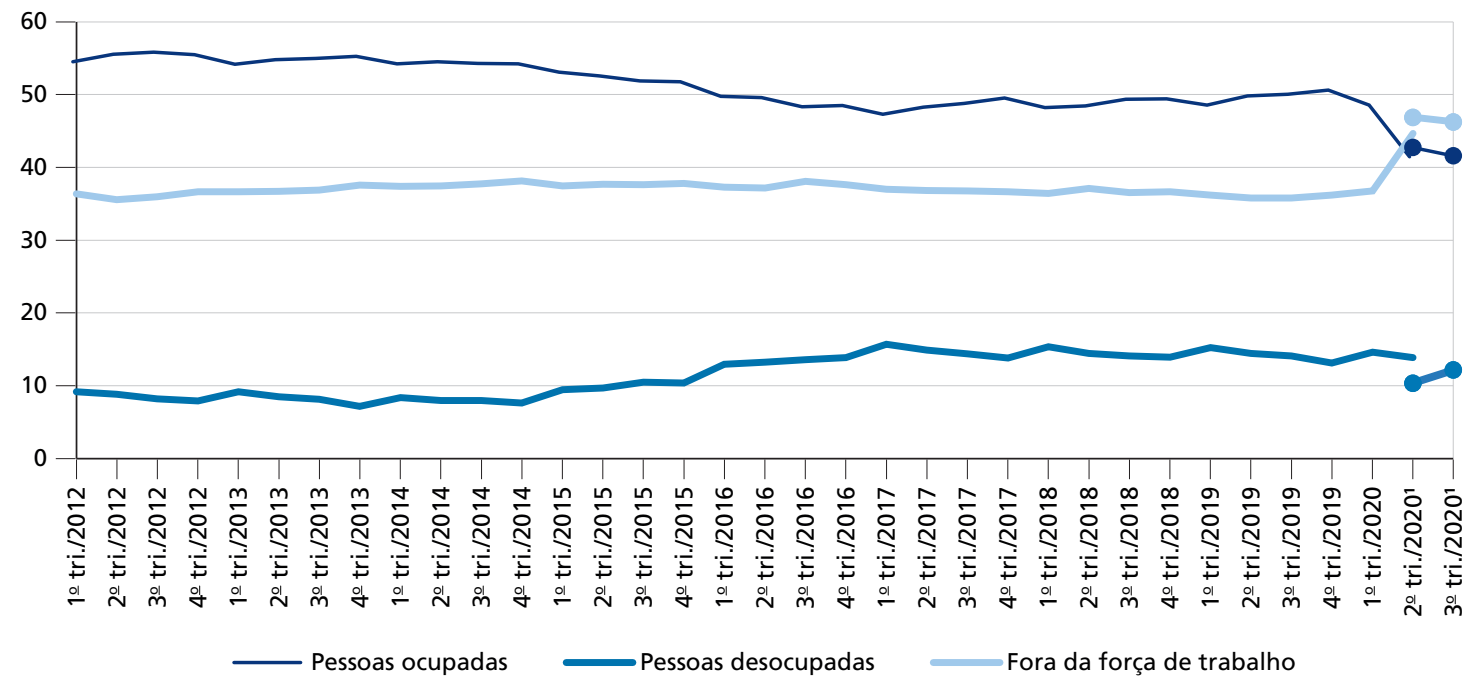

Fontes: PNAD Contínua trimestral (disponível em: <https://bit.ly/2SUu8Pl>); e PNAD Covid-19 (disponível em: <https://bit. ly/35YHxMl>).

Elaboração dos autores.

Nota: ${ }^{1}$ A série pontilhada corresponde aos dados da PNAD Covid-19 agrupados em trimestres. Devido a diferenças metodológicas, a comparação entre as séries deve ser feita com ressalvas.

12. Para maior aprofundamento na compreensão dessa tendência, ver Corseuil e Franca. 
O gráfico 7 mostra a evolução recente da taxa dos jovens nem-nem. Nele, pode-se observar duas tendências. A primeira é a elevação, a partir do primeiro trimestre de 2015, da taxa dos jovens nem-nem maiores de 18 anos, que atinge seu ápice no primeiro trimestre de 2017 e se mantém nesse patamar até o momento anterior à pandemia da Covid-19. A segunda é o aumento expressivo da taxa dos jovens maiores de 18 anos que ficaram sem estudar e sem trabalhar no segundo trimestre de 2020, devido à crise sanitária da Covid-19.

No entanto, esse aumento de jovens sem trabalho e sem estudo não foi observado para os jovens entre 15 e 17 anos, que reduziu em 6 pontos percentuais (p.p.) entre o primeiro e o segundo trimestres de 2020. Os dados não são suficientes para entender o sentido da movimentação dos jovens adolescentes no âmbito da força de trabalho. É possível, contudo, que parte desses tenha saído em busca de trabalho para apoiar a família que perdeu a renda no contexto pandêmico. Uma análise realizada pelo Ministério Público do Trabalho em parceria com o Fundo das Naçóes Unidas para a Infância (UNICEF) entre abril e julho de 2020, com famílias vulneráveis na cidade de São Paulo, identificou um aumento considerável nos casos de trabalho infantil entre crianças e adolescentes (UNICEF alerta..., 2020).

\section{GRÁFICO 7}

Proporção trimestral de jovens sem trabalho e sem estudo (2012-2020) (Em \%)

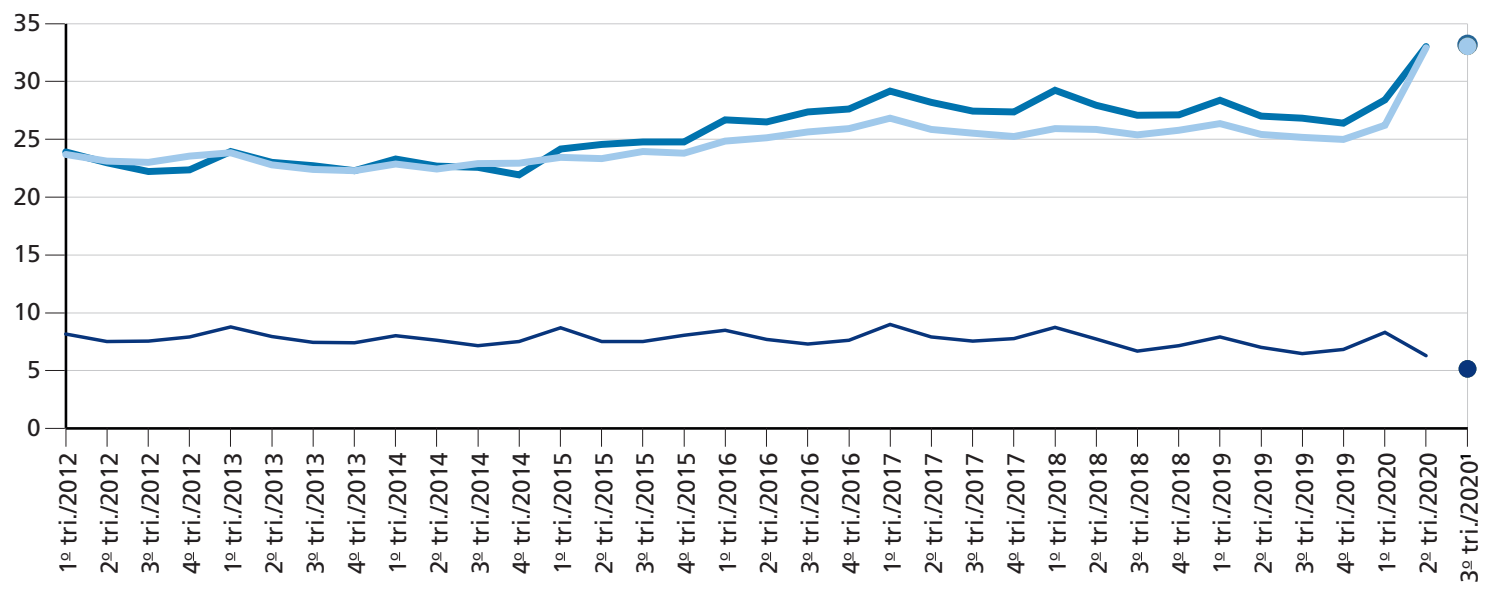

15 a 17 anos $\longrightarrow 25$ a 29 anos

Fontes: PNAD Contínua trimestral (disponível em: <https://bit.ly/2SUu8PI>); e PNAD Covid-19 (disponível em: <https://bit. ly/35YHxMl>).

Elaboração dos autores.

Nota: ' A série pontilhada corresponde aos dados da PNAD Covid-19 agrupados em trimestres. Devido a diferenças metodológicas, a comparação entre as séries deve ser feita com ressalvas.

O gráfico 8 mostra a série de transiçóes que os jovens percorrem para dentro e para fora da categoria dos nem-nem no intervalo de doze meses. Observa-se que os jovens que estão na condição sem estudo e sem trabalho transitam muito mais entre situaçóes de inatividade e de estudo ou trabalho. Com base no gráfico 8, o fluxo dos que estão sem estudar e sem trabalhar para fora dessa condição situa-se, normalmente, acima de 30\%; e entre os jovens que estudam 
ou trabalham, a larga maioria (mais de $80 \%$ ) permanece nessa mesma condição. Esses dados confirmam que transitar entre as situaçóes de trabalho, estudo e inatividade faz parte da trajetória dos jovens e não é uma situação permanente. Todavia, torna-se preocupante quando os períodos de inatividade se tornam longos e levam os jovens a se desengajar do mercado de trabalho e das atividades de educação e treinamento.

GRÁFICO 8

Probabilidade de transição em doze meses dos jovens entre as condições de trabalho e/ou estudo (2013-2020)

(Em \%)

$8 \mathrm{~A}$ - Jovens sem trabalho e sem estudo na primeira entrevista (realizada há 12 meses)

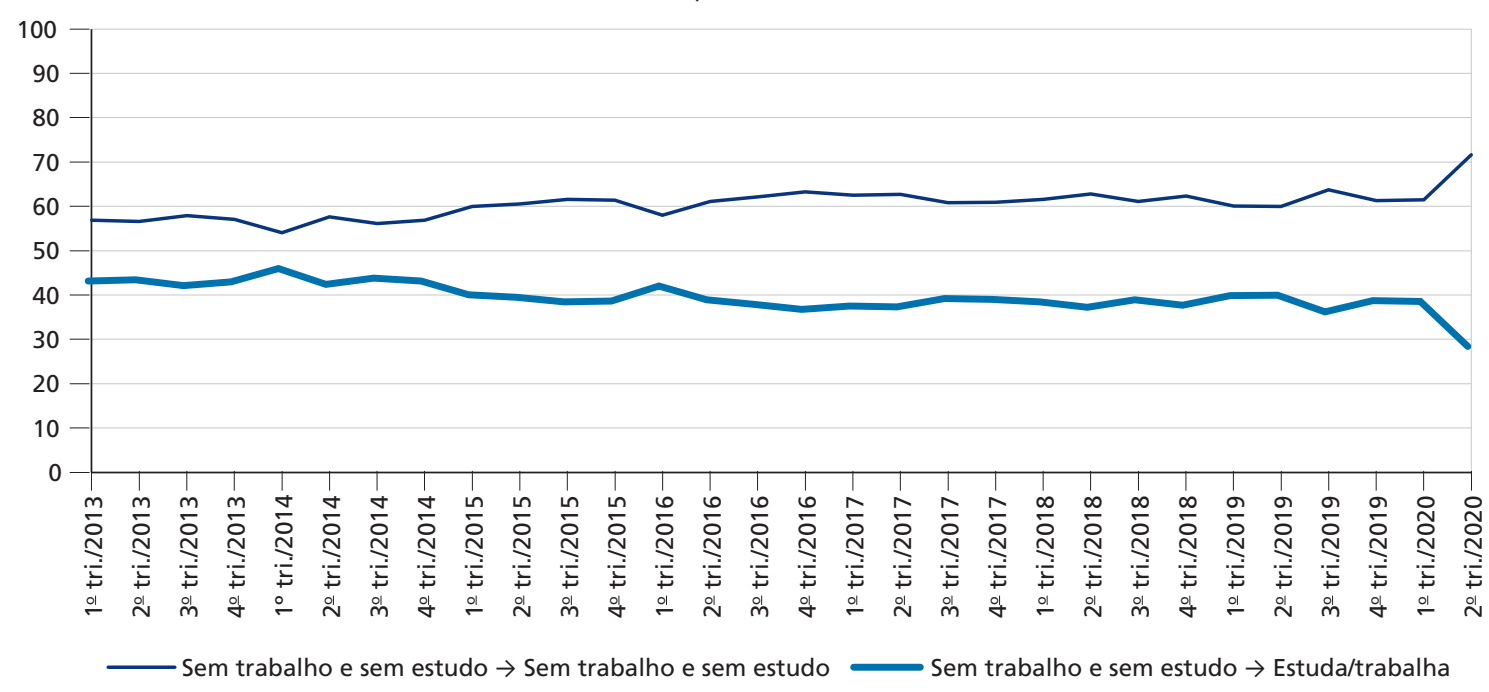

8B - Jovens com trabalho e/ou estudo na primeira entrevista (realizada há 12 meses)

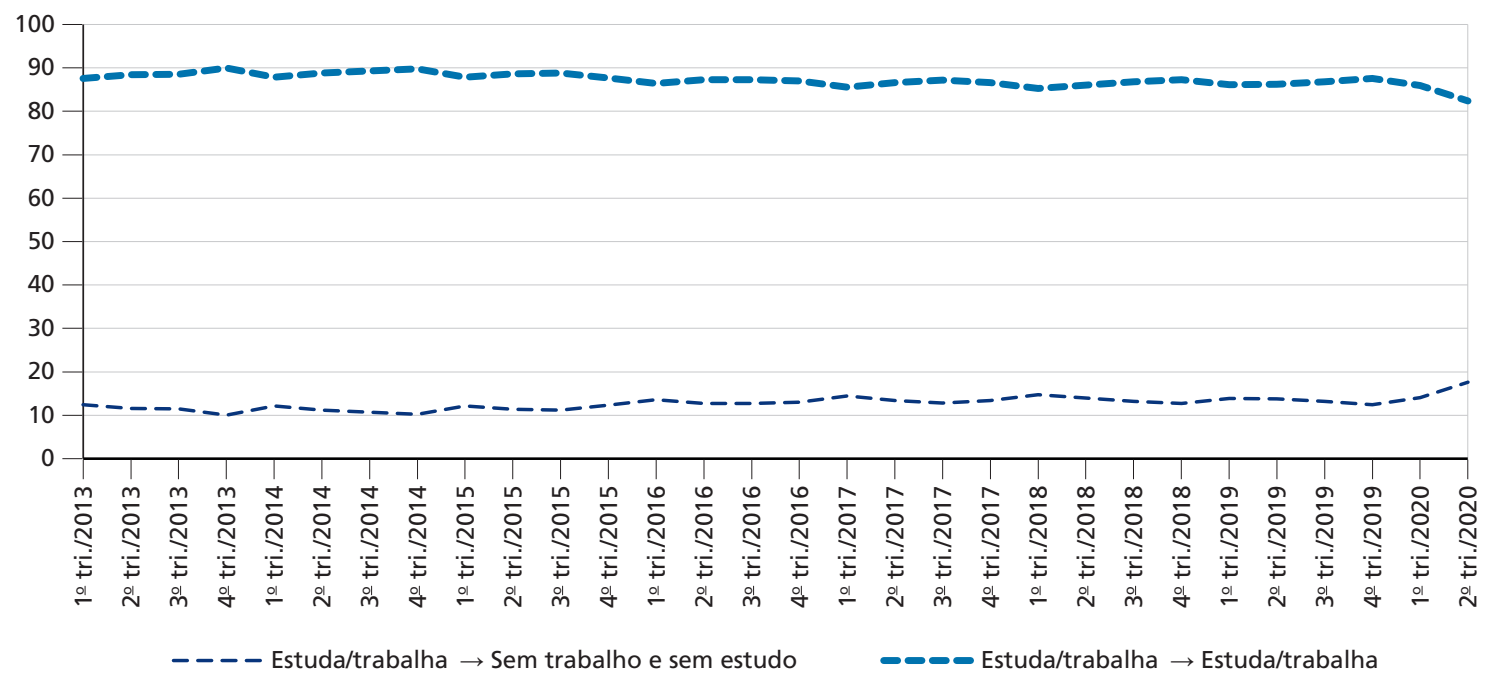

Fonte: Painel longitudinal entre a primeira e quinta entrevistas da PNAD Contínua.

Elaboração dos autores. 
A série de dados do gráfico 8 aponta também que os jovens sem trabalho e sem estudo foram mais afetados pela pandemia da Covid-19 do que aqueles que estavam ocupados ou estudando nos doze meses anteriores. Embora a crise decorrente da pandemia tenha afetado a todos de alguma forma, os jovens que trabalhavam ou estudavam lograram em sua maioria manter a situação. Para aqueles que estavam sem trabalho e sem estudo, por sua vez, houve um fechamento das portas de saída: entre o primeiro e o segundo trimestres de 2020, a probabilidade de saída dessa condiçáa despencou mais de 10 p.p. (de 39\% para 28\%) e o contrário ocorreu com a probabilidade de permanência.

Durante a pandemia, houve expressiva migração dos jovens nem-nem para fora da força de trabalho. Esse movimento é captado pelo gráfico 9 por meio do abrupto aumento de jovens nem-nem na categoria outros, cuja fração cresceu de 3\% para 7\% entre os dois primeiros trimestres de 2020. No âmbito da PNAD Covid-19, a categoria outros agrega a maior parte dos jovens que deixaram de procurar emprego por motivos relacionados à pandemia. Os outros subgrupos de nem-nem, praticamente, não se alteraram no período de captaçáo dos dados da PNAD Covid-19 mostrados aqui.

GRÁFICO 9

Proporção trimestral dos jovens por categoria de nem-nem (2012-2020) (Em \%)
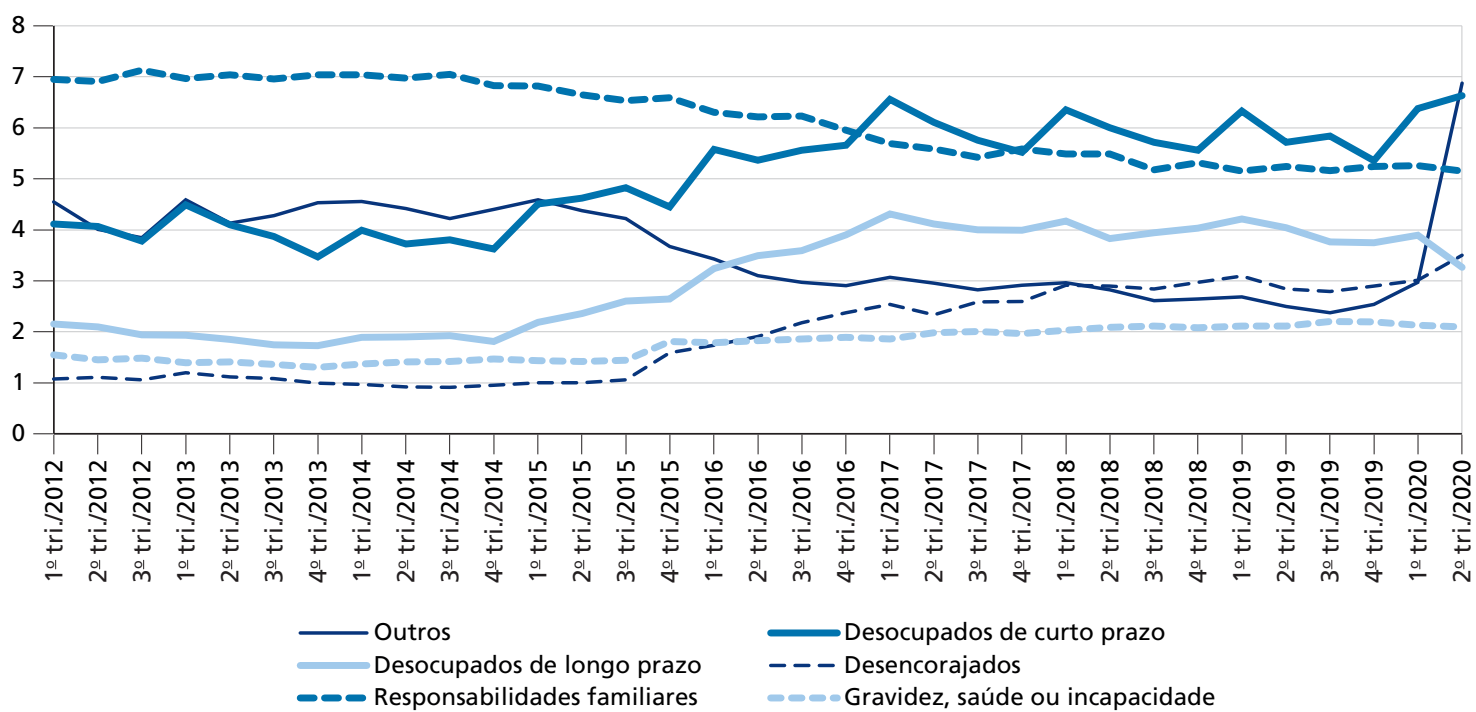

Fontes: PNAD Contínua trimestral (disponível em: <https://bit.ly/2SUu8PI>); e PNAD Covid-19 (disponível em: <https://bit. ly/35YHxMl>).

Elaboração dos autores.

O gráfico 10 desagrega os jovens que estavam sem trabalho e sem estudo nos doze meses anteriores e analisa a probabilidade de saída dessa condição no fim do período. Primeiramente, nota-se que, para aqueles que se encontravam como desocupados de curto prazo, a chance de transitar para outras situaçóes no mercado de trabalho é muita alta em todo o período, embora já tivesse sido maior no período anterior ao primeiro trimestre de 2015 . 
Observa-se, também, que a probabilidade entre os desencorajados de sair da situação dos nem-nem, equivalente a $34 \%$, não chega a ser tão elevada como a dos desocupados, mas é significativa, quando comparada com a dos demais tipos de nem-nem que estáo fora da força de trabalho. Para os jovens sem trabalho e sem estudo em função de gravidez, saúde ou incapacidade e também para aqueles que estão nessa situação por responsabilidades familiares, a condição de nem-nem é mais difícil de ser revertida, pois somente $20 \%$ e $26 \%$ desses, respectivamente, retornam ao trabalho ou ao estudo após doze meses.

A crise da pandemia da Covid-19 trouxe como consequência o fechamento das portas de saída para os jovens nem-nem migrarem dessa situação. Conforme apontam os dados do gráfico 10, as probabilidades para os nem-nem desocupados de curto e longo prazo saírem dessa condição caíram em 13 p.p. e 11 p.p., respectivamente, entre o primeiro e o segundo trimestres de 2020; para os desencorajados, 8 p.p.; e, para os nem-nem por responsabilidades familiares, a queda foi de 5 p.p. para o mesmo período. Por sua vez, os jovens que estavam fora da escola e da força de trabalho, por conta de gravidez, saúde ou incapacidade, não registraram mudança perceptível, uma vez que eles já não usufruíam de grande mobilidade. Todavia, a queda mais vertiginosa ocorreu no âmbito da categoria outros, que despencou 20 p.p. em um único trimestre, um valor sem precedentes na série histórica.

GRÁFICO 10

Probabilidade de transição em doze meses dos jovens sem trabalho e sem estudo para a condição de estudo e/ou trabalho - por categorias (2013-2020) (Em \%)

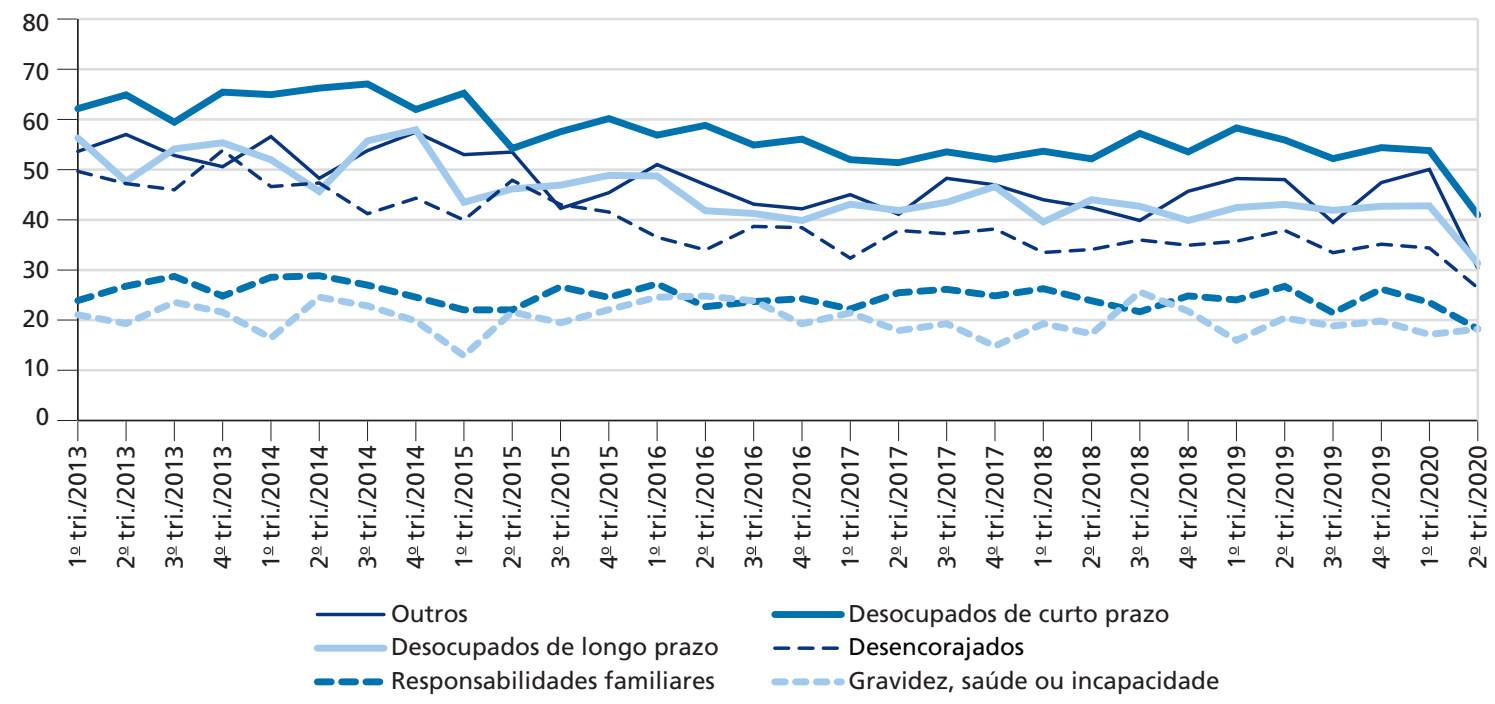

Fonte: Painel longitudinal entre a primeira e quinta entrevistas da PNAD Contínua.

Elaboração dos autores.

Os dados sobre educação e trabalho dos jovens nem-nem durante a crise sanitária são preocupantes, especialmente, pelas perspectivas da elevada proporção de jovens nem-nem que deixaram de buscar trabalho devido à pandemia. Felizmente, a cobertura de proteção social 
desses indivíduos tem sido abrangente no auge desse período. De acordo com os dados do gráfico 11, as coberturas do Auxílio Emergencial ${ }^{13}$ e do Programa Bolsa Família alcançaram cerca de $80 \%$ dos grupos de nem-nem desencorajados e daqueles por afazeres domésticos e, aproximadamente, $60 \%$ dos nem-nem desocupados e os que estáo nessa situação por problemas de saúde, incapacidade e gravidez.

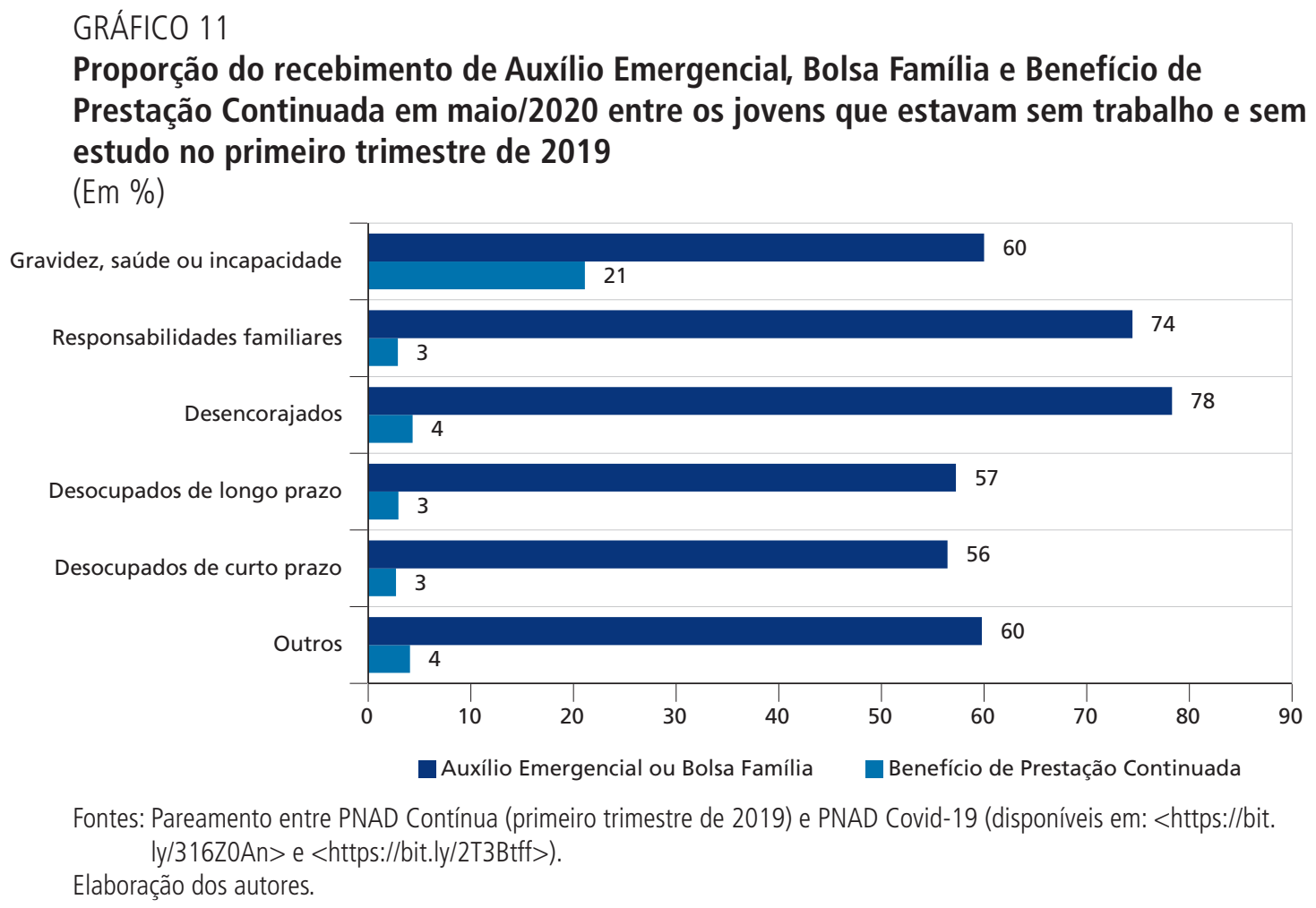

\section{CONSIDERAÇÕES FINAIS}

Compreender que os jovens nem-nem se constituem em um grupo heterogêneo é essencial para a formulação de políticas públicas que visam à sua reintegração no mercado de trabalho. O conhecimento da composição, do tamanho e das características de cada subgrupo dos nemnem pode permitir aos tomadores de decisóes (policymakers) definirem, com mais propriedade, quais açóes devem ser priorizadas em cada situação.

Ao longo deste estudo, mostramos que os jovens nem-nem apresentam diferentes vulnerabilidades que contribuem para ficarem sem estudar e sem trabalhar. Além disso, os dados aqui analisados comprovaram a intensa transitoriedade existente na condição dos jovens nem-nem, confirmando sua característica de não permanência. Alguns grupos, como os dos

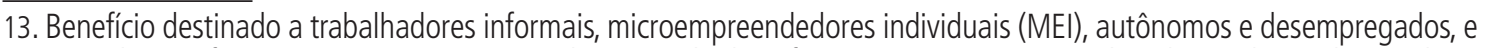
tem por objetivo fornecer proteção emergencial no período de enfrentamento à crise causada pela pandemia da Covid-19. 
desocupados de curto e longo prazo, possuem maiores probabilidades de se encontrarem em outra condiçáo de trabalho e estudo ao longo de um período de doze meses, comparativamente aos grupos que se situam fora da força de trabalho.

Os grupos de nem-nem desengajados do mercado de trabalho são mais vulneráveis que os nem-nem desocupados e apresentam maiores dificuldades para saírem dessa situação. Os dados revelaram que os primeiros estáo mais representados entre as mulheres, os negros, os jovens de mais baixa escolaridade e os mais pobres.

O Auxílio Emergencial assistiu amplamente os jovens nem-nem durante o auge da crise sanitária da Covid-19, chegando a alcançar cerca de $80 \%$ da categoria dos desencorajados e dos que estavam nessa situação por afazeres domésticos. No entanto, as perspectivas para o período pós-pandemia são muitos preocupantes, pois um dos efeitos da crise sanitária foi o fechamento das portas de saída para esses jovens migrarem para outras condiçôes de estudo e trabalho, ampliando o grupo dos jovens nem-nem situados fora da força de trabalho.

Os subgrupos dos nem-nem que integram a força de trabalho (desocupados de curto e longo prazo) são mais facilmente alcançados pelas políticas públicas de ativação da oferta e da demanda do mercado de trabalho, porque, em geral, estáo mais disponíveis à participaçáo em programas de treinamento profissional e mais bem-informados em relaçáo às ofertas existentes no mercado de trabalho. Em oposição, os grupos de jovens nem-nem fora da força de trabalho formam um contingente difícil de ser alcançado pelas políticas públicas. Como náo estudam e não buscam trabalho, não mantêm cadastro atualizado nos serviços de intermediação ou das escolas. Dessa forma, seu alcance, por parte das medidas governamentais, demanda ações de busca de ativa.

Finalmente, tendo em vista as elevadas vulnerabilidades dos jovens nem-nem, agravadas pela pandemia da Covid-19, seria fundamental a implementação de uma estratégia de políticas públicas capaz de enfrentar os dois principais desafios apontados aqui: i) a desocupaçáo de longo prazo dos jovens sem estudo e sem trabalho, que pode refletir na falta de motivaçáo e levar os jovens ao desalento, trazendo consequências negativas para o resto da vida laboral; e ii) a elevada proporçấo de jovens nem-nem que já se encontra desengajada do mercado de trabalho e da educação.

Essa intervenção poderia considerar a heterogeneidade desse grupo e combinar medidas de elevação de escolaridade, articuladas às açóes de qualificação; de assistência à procura de emprego; de treinamento das habilidades socioemocionais; e de mentorias individuais. ${ }^{14}$ Existe a necessidade de maior integração entre as várias políticas e iniciativas dirigidas para o público jovem, especialmente para os jovens que estão "nem-nem".

14. Um detalhamento maior desta proposta pode ser encontrado em Ipea (2020). 


\section{REFERÊNCIAS}

EUROFOUND - EUROPEAN FOUNDATION FOR THE IMPROVEMENT OF LIVING AND WORKING CONDITIONS. Exploring the diversity of NEETs. Luxembourg: Eurofound, 2016.

GUIMARÃES, N.; MARTELETO, L.; ALVES, M. B. Trajetórias e transiçóes: os múltiplos e difíceis caminhos dos jovens brasileiros no mercado de trabalho. Brasília: OIT, 2016.

IBGE -INSTITUTO BRASILEIRO DE GEOGRAFIA E ESTATÍSTICA. Pesquisa Nacional por Amostra de Domicílios Contínua. Notas técnicas: versão 1.7. Ipea: Rio de Janeiro, 2020. Disponível em: <https://bit.ly/3nOR80m>. Acesso em: 14 out. 2020.

IPEA - INSTITUTO DE PESQUISA ECONÔMICA APLICADA. Brasil pós-Covid-19: contribuiçóes do Instituto de Pesquisa Econômica Aplicada. Ipea: Brasília, 2020. Disponível em: <https://bit.ly/34yq6RS>. Acesso em: 14 out. 2020.

MASCHERINI, M. Origins and future of the concept of NEETs in the European policy agenda. In: O'REILLY, J. et al. (Eds.). Youth labor in transition: inequalities, mobility and polices in Europe. New York: Oxford Scholarship, 2019. p. 503-528.

UNICEF alerta para aumento de incidência do trabalho infantil durante a pandemia em São Paulo. UNICEF, 18 ago. 2020. Disponível em: <https://uni.cf/3jIBwca>. Acesso em: 14 out. 2020.

\section{BIBLIOGRAFIA COMPLEMENTAR}

CAMARANO, A. A.; KANSO, S.; LEITÃO, J. M. Transição para a vida adulta: mudanças por período coorte. In: CAMARANO, A. A. Transiçáo para a vida adulta ou vida adulta em transiçáo? Rio de Janeiro: Ipea, 2006. p. 95-136.

COSTA, J.; ROCHA, E.; SILVA, C. Voces de la juventud en Brasil: aspiraciones y prioridades. In: NOVELLA, R. et al. (Eds.). Millennials en América Latina y el Caribe: ¿trabajar o estudiar? Washington, D.C.: BID, 2018. 
